\title{
REQUESTED COMMENT
}

\author{
Tirone E. David, MD, Toronto, Ontario, Canada
}

The concerns of Dr. Gallo and associates regarding our technique of reconstruction of the aortic root with preservation of the aortic valve are valid. We also expressed concerns about it in our original article. ${ }^{1}$ However, we have now preserved the aortic valve in more than 50 patients with aortic root aneurysm and we have had only one late failure, which occurred in a teenager with Marfan's syndrome. ${ }^{2}$ The aortic valve function has remained stable up to 5 years in the remaining patients.

Patient selection is probably the single most important factor in the outcome of any valve repair. In patients with aortic root aneurysm the aortic valve should be repaired only when the leaflets are normal. In a normal leaflet the length of its base is approximately 1.5 times longer than the length of its free margin. Next, if the patient has severe aortic valve insufficiency, the cause of valve dysfunction must be determined and the appropriate surgical technique used. When there is enlargement of both the aortoventricular junction and the sinotubular junction, an

From the Division of Cardiovascular Surgery, The Toronto Hospital, Toronto, Ontario M5G 2C4, Canada.

J THORAC CARDIOvasc SuRg 1995;109:1013

Copyright $(\mathcal{C} 1995$ by Mosby-Year Book, Inc. $0022-5223 / 95 \$ 3.00+0 \quad \mathbf{1 2 / 8 / 6 0 3 3 3}$ aortic annuloplasty and resuspension of the leaflets in a Dacron fabric tube is necessary (we refer to this technique as "reimplantation of the aortic valve"). When only the sinotubular junction is enlarged, supraannular reconstruction of the aortic root with or without reimplantation of the coronary arteries is done (we refer to this technique as "remodeling of the aortic root").

By using these techniques in carefully selected patients we have been able to provide excellent clinical results in 51 of 53 patients operated on during the past 5 years.

We remain carefully optimistic about these operative techniques. Observations such as those of Gallo and colleagues are important as surgeons introduce new operative techniques and they stress the necessity of continuing follow-up of these patients.

\section{REFERENCES}

1. David TE, Feindel CM. An aortic valve-sparing operation for patients with aortic incompetence and aneurysm of the ascending aorta. J ThORAC CARDIOvasC SURG 1992;103:617-22.

2. David TE, Feindel CM, Bos J. Repair of the aortic valve in patients with aortic insufficiency and aortic root aneurysm. J ThoraC CARDiovasc SuRg [In press].

\section{LIDOFLAZINE AND MYOCARDIAL PROTECTION}

\author{
B. Akpinar, MD, ${ }^{*}$ H. Vanerman, MD, and F. Wellens, MD, Aalst, Belgium
}

Lately interest in the myocardial protective effects of lidoflazine (Janssen Research Foundation, Beerse, Belgium) has been renewed. Although many clinical and experimental studies on this drug have been conducted, the mechanism of its cardioprotective effect has not been completely established. Selective calcium entry blocking activity of the drug was not demonstrated, but the latest

From O.L.V. Hospital, Department of Thoracic and Cardiovascular Surgery, Aalst, Belgium.

*Present address: Florence Nightingale Hospital, Department of Thoracic and Cardiovascular Surgery, Istanbul, Turkey.

J THORAC CardiovasC SURG 1995;109:1013-4

Copyright (C) 1995 by Mosby-Year Book, Inc.

$0022-5223 / 95 \$ 3.00+0 \quad \mathbf{1 2 / 8 / 5 8 0 0 2}$ studies focus more on the nucleoside transport inhibitory effect of lidoflazine. ${ }^{1,2}$

For more than a decade, we have been using lidoflazine pretreatment, moderate hypothermia, and a single period of crossclamping for coronary artery operations, with excellent results. We wanted to make a comparative study to evaluate the myocardial protective effect of lidoflazine using hemodynamic, biochemical, and clinical parameters.

Fifty patients, 25 in each group, were selected according to their age, sex, and left ventricular ejection fraction. Patients older than 70 years of age, patients with combined procedures or reoperations, and patients with an impending myocardial infarction were excluded from the study. Left ventricular ejection fraction less than $30 \%$ was also an exclusion criteria. Data on both groups A and B are shown in Table I.

In group $\mathrm{A}$, in which lidoflazine and a single crossclamp 